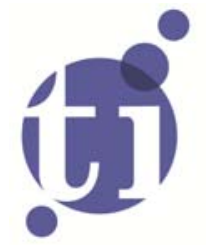

\title{
Space and Knowledge Spillovers in European Regions -
}

\section{The Impact of Different Forms of Proximity on Spatial Knowledge Diffusion}

\author{
Andrea Caragliur \\ Peter Nijkamp²
}

${ }^{\prime}$ Building Environment Science and Technology, Politecnico di Milano, Italy;

2 Faculty of Economics and Business Administration, VU University Amsterdam, and Tinbergen Institute, The Netherlands. 
Tinbergen Institute is the graduate school and research institute in economics of Erasmus University Rotterdam, the University of Amsterdam and VU University Amsterdam.

More TI discussion papers can be downloaded at http://www.tinbergen.nl

Tinbergen Institute has two locations:

Tinbergen Institute Amsterdam

Gustav Mahlerplein 117

1082 MS Amsterdam

The Netherlands

Tel.: +31(0)205251600

Tinbergen Institute Rotterdam

Burg. Oudlaan 50

3062 PA Rotterdam

The Netherlands

Tel.: +31(0)10 4088900

Fax: $+31(0) 104089031$

Duisenberg school of finance is a collaboration of the Dutch financial sector and universities, with the ambition to support innovative research and offer top quality academic education in core areas of finance.

DSF research papers can be downloaded at: http://www.dsf.nl/

Duisenberg school of finance

Gustav Mahlerplein 117

1082 MS Amsterdam

The Netherlands

Tel.: +31(0)20 5258579 


\title{
Space and Knowledge Spillovers in European Regions - The Impact of Different Forms of Proximity on Spatial Knowledge Diffusion
}

\author{
Andrea Caragliua, ${ }^{\mathrm{ab}, *}$ and Peter Nijkamp ${ }^{\mathrm{b}, \mathrm{c}}$ \\ ${ }^{a}$ Building Environment Science and Technology \\ ${ }^{\mathrm{b}}$ Faculty of Economics and Business Administration \\ Politecnico di Milano \\ Department of Spatial Economics \\ Piazza Leonardo da Vinci, 32 \\ VU University \\ 20133 Milano (MI) \\ De Boelelaan 1105 \\ Italy \\ 1081 HV Amsterdam \\ * Corresponding author \\ and Tinbergen Institute, The Netherlands
}

\begin{abstract}
Usually, the diffusion of a non-rival market knowledge externality - called a Knowledge Spillover (KS) - is related to geographical proximity. In this paper we explore the channels through which knowledge spreads. Compared with earlier work on KS measures, this study makes a step forward by calculating KS (as a balance of positive and negative absolute knowledge flows) on the basis of different proximity matrices. In particular, we focus on the relational, social, technological, and cognitive channel, along with the traditional geographical channel. In the light of previous studies on KS, we examine: (i) which types of proximity enhance or hamper the outward flow of knowledge; and (ii) whether the local endowment of absorptive capacity reduces such a flow. Our results show that KSs vary across alternative definitions of proximity. The parameter estimates of such a KS model show interesting patterns, with geographical and cognitive proximity having the highest explanatory power among all the types of proximity considered. Local absorptive capacity is found to be negative only when a region is surrounded by regions with similarly high levels of absorptive capacity. Furthermore, outward KSs decrease as geographical, relational, social, technological and cognitive distance increase. This points to the emergence or existence of large clusters of regions ('absorptive capacity clubs'), where relational, social, technological and cognitive proximity lock-in maximizes the returns to local investment in R\&D.
\end{abstract}

Keywords: knowledge spillover, total factor productivity, proximity, absorptive capacity, knowledge production function

Pn606ac 


\section{Introduction}

Since the early literature on human capital, countless theoretical and empirical studies have aimed to identify knowledge as the main determinant of economic performance. Enhanced econometric techniques accompanied by the availability of rich data sets on, for instance, innovations, education, patents or patent citations - have fostered a wealth of studies on the spatial characteristics which impact on the flow of knowledge across space (Faggian and McCann, 2006). These studies proved the existence of non-market knowledge externalities, defined as Knowledge Spillovers (KSs), which travel in space around the origin of new knowledge, but are subject to dire distance-decay processes. The identification of KS mainly took place by empirically verifying over what distance on average patent citations travel, or through the application of recent advances in spatial econometrics to regional knowledge production functions (henceforth, KPFs) or to regional growth regressions (Acs et al., 1994).

Recently, a new approach was proposed to capture potential KSs, through an application of the notion of a spatial filter applied to the dependent variable of a traditional KPF (Caragliu and Nijkamp, 2012; Caragliu and Del Bo, 2011). However, the notion of space underlying this work is purely geographical. While geographical space is often a good proxy for the implicit channels along which knowledge flows, it certainly fails to make such channels explicit, and therefore provides only limited insight into the topic of KS, other than the pure identification of their existence, and an indication of the relevance of distance-decay functions. Such a shortcoming has been partly motivated by the relative lack of data and computing power on alternative notions of space. Regional scientists and economists have rarely tried to overcome this gap, and have seldom attempted to encompass in one single study different notions of space.

In this paper we aim to fill this gap, and propose a critical review of previous findings on the notions of proximity, which allow us to identify five main typologies of space (geographical, relational, social, technological, and cognitive), over which knowledge is expected to travel. These five types are then used to define five weight matrices, on the basis of which the above-mentioned econometric transformation is applied in order to study outward knowledge spillovers (henceforth, OKSs).

This paper is organized as follows. In Section 2 we resume the long-standing debate on the dichotomy of knowledge as a public versus a private good, thus motivating our measure of KSs, and provide a critical review of the different notions of space and proximity employed in theoretical and applied work on KSs. We also provide an explanation of the possible underlying mechanisms that yield a rationale for the use of more complex notions of proximity in the field of KS. Section 3 then summarizes the methodology for the empirical estimation of our model. The data set collected for the present paper and our measures of proximity are explained in Section 4. The estimation results are presented in Section 5, while Section 6 presents graphical evidence on our empirical findings. Finally, Section 7 makes some concluding remarks and brief comments on the policy implications of our findings. 


\section{Literature review}

\subsection{Proximity in regional research}

From an economic standpoint, knowledge can in most cases be defined as a partially public (i.e. non-rival and non-excludable) good. Its partially non-rivalrous nature has also been pinpointed in classical writings. In 1813, for instance, Thomas Jefferson writes in a letter to Isaac Mc Pherson "If nature has made any one thing less susceptible than all others of exclusive property, it is the action of the thinking power called an idea....Its peculiar character...is that no one possesses the less, because every other possesses the whole of $i t$ " (Washington, 1853, p. 180; see also Suber, 2009). The imperfect excludability of knowledge is, on the contrary, modelled in Lucas (1988), where agents invest in their own education without fully internalizing the benefits stemming from such investment which also accrue to the rest of the society. It therefore seems plausible to assume that at least part of the codified and tacit knowledge produced in a region transmits to other areas because of imperfect rivalry and imperfect excludability.

In the process of spatial diffusion, knowledge faces distance-decay effects. Conceptual and empirical research in regional science has addressed and clarified the implications of spatial barriers with varying degrees of success (Krugman, 1998). However, recent advances in spatial economics have provided a rich set of theories explaining the complex forms of proximity in economic interactions. In the field of knowledge production and diffusion, there is a general consensus that not all the positive fallout of knowledge production is locally retained (Jaffe et al., 1993; van Geenhuizen and Nijkamp, 2012); in fact, some scholars (e.g. Shearmur and Bonnet, 2011) even argue that the local production of knowledge is uncorrelated with local economic performance. Such critiques call for a profound analysis of the economic mechanisms that drive the ways in which KSs travel across space.

Various attempts have been made since the mid-1950s to systematize the literature on different forms of proximities. Traditionally, economic models have tended to ignore the effects of distance among actors as a major determinant of the outcome of economic interactions. While this relative lack of attention stimulated Walter Isard's (e.g. Isard, 1956) early contributions and the very birth of regional science, only relatively recently has economics begun to include space explicitly into formal models (for an overview, see, e.g., van den Bergh et al., 1998). In the last decade of the twentieth century, regional scientists stressed more aspects of the relevance of space in economic interactions, and prompted the analysis of alternative forms of proximities beyond just geographical space. This was true in particular for the 'learning region' approach (e.g. institutional proximity: see Lundvall and Johnson, 1994) and the 'milieu innovateur' and the 'industrial district' theories (which focused more on relational proximity: see Aydalot, 1986; Camagni, 1991; Becattini, 1992). However, such literature has often, and mostly because of previous limitations of computing power in econometric software, been unable to account for more complex definitions of proximity, as opposed to a definition based simply on geographical space. The contributions by the New Economic Geography (Fujita et al., 1999) are noteworthy here. 
Around the mid-1990s, there was a resurgence of applied studies, stimulated by pioneering work on the economic rationale for alternative approaches to proximity (Crevoisier, 1996; Boschma, 2005; Torre and Gilly, 1999; Capello, 2009), and made possible by the increase in the computing power of standard econometric software. While the objectives of these studies were sometimes diverse (mostly concerning the determinants of KSs and regional growth), all share an increased interest in the real channels through which physical distance affects economic interactions. In fact, physical distance in standard KS studies can be considered as a 'black box' As pointed out in Grosjean (2011), "distance matters in itself, but is also a proxy for other determinants of familiarity".

Various forms of proximity have been identified as the real channels through which knowledge can be transmitted. Figure 1 shows most definitions of proximity as they have been variously framed over the past two decades, in the literature summarized above.

A first school of thought identifies in relational proximity a cause for the emergence of local increasing returns to regional development. According to the milieu innovateur school, developed by the GREMI group, ${ }^{1}$ regional stocks of knowledge will accumulate through cooperative learning processes, enabled and fostered by spatial proximity (which enters the theoretical foundations of the milieu literature as a form of 'atmosphere' effects), network relations (where long-distance relationships can be as effective as face-to-face contacts in a selected set of knowledge-intensive relationships), socio-cultural interaction, and creativity. According to this view, the thickness of relationships among local actors enhances the likelihood of innovative types of behaviour, which in turn foster economic performance. More recently, network components associated with the notion of relational proximity have also been analysed in interesting empirical studies on the role of relational proximity as means of fostering KSs (see, e.g., Maggioni and Uberti, 2009).

Simultaneously, the learning region theory ${ }^{2}$ stresses the role of institutional distance in economic interactions, via an insightful analysis of the interactions between local actors belonging to a system of homogeneous socio-economic and institutional environment. Conceptually similar to the notion of institutional proximity is the idea that organizational proximity may also make economic transactions easier. However, in this case much confusion arises when different schools use this label to address (at least partially) different concepts. In particular, the French school of proximity dynamics (Bellet et al., 1993) stressed the relevance of relationships in the effects of low levels of organizational dissimilarities among actors within pre-determined social structures. This implies a partial overlapping with the milieu innovateur approach to proximity.

\footnotetext{
${ }^{1}$ The GREMI (Groupe de Recherche Européen sur les Milieux Innovateurs) was created by Philippe Aydalot in 1984, and focused its research on the determinants of the spatial concentration of small firms.

${ }^{2}$ See Lundvall and Johnson (1994); Morgan (1997).
} 


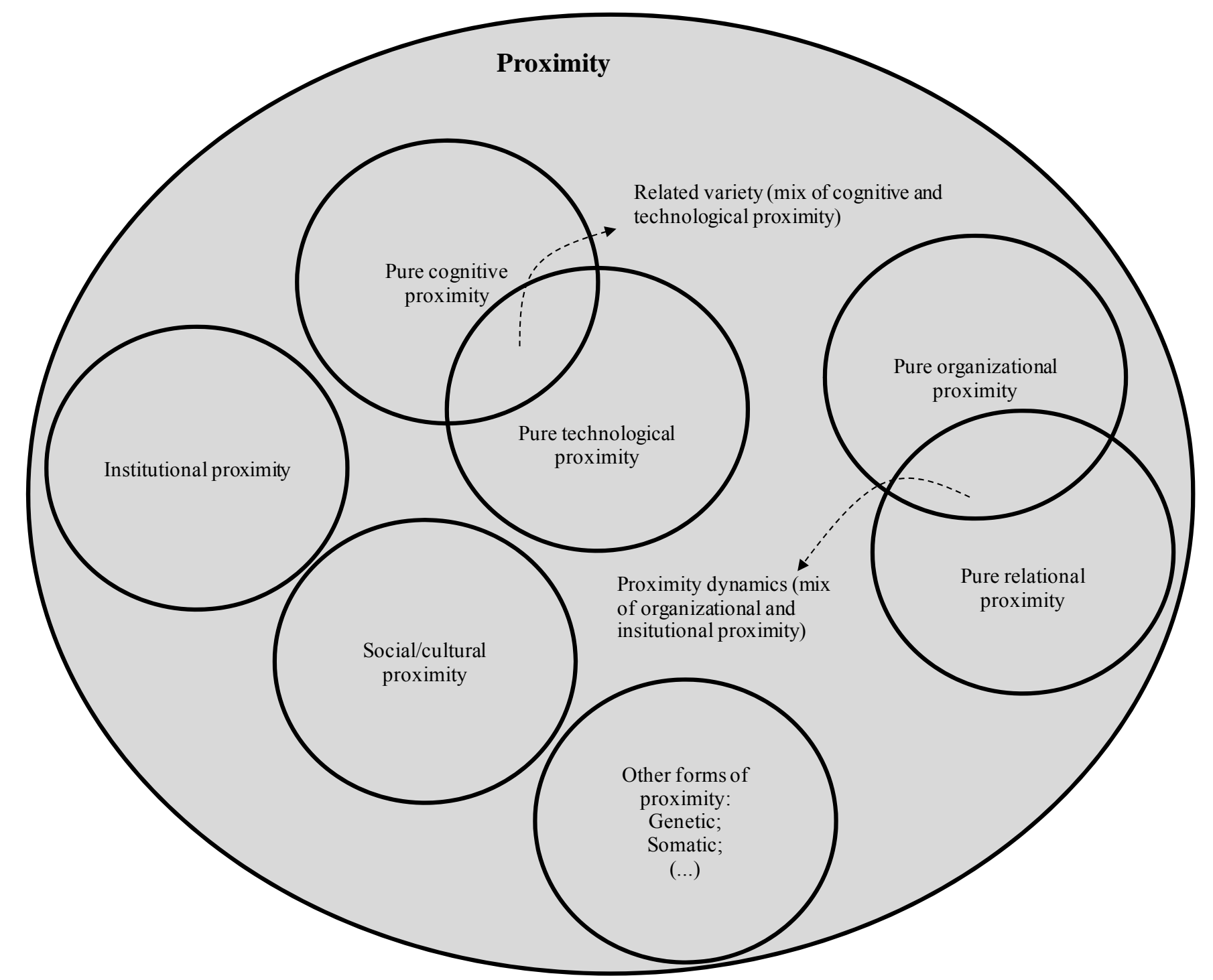

Figure 1. A classification of proximities

Note: The empty brackets in the bottom circle suggests other possible definitions of proximity in the KS literature. 
Analogously, some confusion has arisen concerning the notions of cognitive and technological proximity. The latter has mainly been the focus of industrial organization studies (Orlando, 2004; Jaffe and Trajtenberg, 1999), where, along with the impedance offered by geographical space, knowledge is found to travel more easily across narrowly-defined, and compatible, technological classes. However, a recent and successful wave of studies based on the notion of "related variety" (Broekel and Boschma, 2012) finds that cognitive proximity may, to a certain extent, increase the likelihood of cross-fertilization among actors (within a region). This cross-fertilization requires that people speak the same scientific language (i.e. they belong to the same technological paradigm), while at the same time they are separated in terms of narrower technological classes. This in turn generates a mechanism of creative resonance based on the pool of ideas from relatively different technologies available within the same technological class (hence the term "related variety") which ultimately leads to innovation. Our definition of cognitive proximity follows these ideas, extending this concept from within-region to cross-regional technological cross-fertilization. ${ }^{3}$

All these definitions of proximity do not imply that the distance-decay effect of economic interactions is dead. In fact, applied studies find that all these forms of proximity complement the role of geographical distance as a factor which impedes the flow of knowledge. This mutual complementarity is based on the notion of knowledge tacit-ness. According to Polanyi's work (Polanyi, 1967), standard, codifiable knowledge can be disentangled from what cannot be easily conveyed in written form, and thus formalized. This relates to the dichotomy know-what versus know-how, the latter residing in people's minds and not being transferrable without some loss of relevant information (Johnson et al., 2002). If knowledge is really at least partially tacit, then it travels more easily across shorter distances, since it requires other forms of contact between individuals to be understood, and efficiently decoded and deployed (Howells, 2002).

It should finally be noted that the concept of social and cultural proximity can be linked to the concept of social capital. In the 1980s and 1990s, some influential studies (Coleman, 1988; Putnam et al., 1993; Putnam, 2000; Fukuyama, 1995) attracted the attention of academicians, practitioners and policy makers on the interesting issue of how norms, networks, and institutions (in a single expression, social values) determine the way societies interact. Social incentives are at the heart of this literature. Do more intense interactions between people generate a greater sense of community? Does a higher level of trust among citizens reduce the transaction costs associated with each interaction, and if so, through which channels? According to most studies on social capital, the answer to such questions is "yes". Because social capital is inherently space-specific, and cannot be transplanted without incurring disproportionate costs, inter-regional differences in social capital may hamper the flow of knowledge across space (Agrawal et al., 2006).

\footnotetext{
${ }^{3}$ Because cross-fertilization from technologically-proximate classes definitely alters the perception of the world of agents who are exposed to such knowledge, we posit that cognitive proximity between pairs of regions may also be compatible with a narrower definition. "Cognitive proximity, broadly understood, denominates similarity in the way people perceive, interpret, understand and evaluate the world" (Hüber, 2011). In fact, the notion of cognition implies "the mental process of knowing, including aspects such as awareness, perception, reasoning, and judgment" (The American Heritage Dictionary of the English Language, 2000).
} 
So far, this rich (and growing) literature has seldom brought together these somewhat orthogonal areas of research. ${ }^{4}$ In the present study, we integrate all these relevant views on proximity and adopt an econometric transformation designed by the authors to measure potential KSs according to each of these forms of proximity.

\subsection{Vehicles of knowledge transfer}

Section 2.1 provided a synthesis of the different ways in which proximity has been variously deployed over the years in regional science. Although empirical analyses with respect to all these channels of knowledge transfer have not yet been carried out, the literature offers examples of empirical studies which explore the mechanisms underlying each form of proximity in the process of knowledge diffusion. In other words, how does knowledge physically spread? Are those who advocate the "death of distance" (e.g. Cairncross, 1997) right? Table 1 summarizes some possible channels through which knowledge may actually spread.

Table 1. Proximity concepts and related vehicles of knowledge transfer

\begin{tabular}{lccc}
\hline $\begin{array}{l}\text { Type of } \\
\text { proximity }\end{array}$ & $\begin{array}{c}\text { Channels through which knowledge } \\
\text { spreads }\end{array}$ & Type of indicator & $\begin{array}{c}\text { Mechanisms facilitating } \\
\text { knowledge diffusion }\end{array}$ \\
\hline \hline Geographical & Face-to-face contacts & $\begin{array}{c}\text { Differences in } \\
\text { regional stocks }\end{array}$ & Higher probability of meeting \\
Social/cultural & Parallel decisions, taken because & Differences in & Lower communication costs \\
& cultural values are similar & regional stocks & \\
Technological & Technological spillovers & $\begin{array}{c}\text { Differences in } \\
\text { regional stocks }\end{array}$ & $\begin{array}{c}\text { Higher probability of cross- } \\
\text { fertilization, mostly through }\end{array}$ \\
& Non-verbal communication, tacit & Differences in & Sharing of a common \\
knowledge & regional stocks & communication code \\
& Flows between & Lower transaction costs \\
Informal networks & pairs of regions & \\
\hline
\end{tabular}

Geographical proximity, which lies behind most current studies of knowledge transfer, is at best a proxy for the real underlying channels of knowledge transfer. It is implicitly based on the assumption that knowledge spreads only via face-to-face contacts, implying that the closer the agents are, the higher the probability of meeting.

This concept hides some possible real channels of knowledge flows across space. For instance, social proximity among agents may imply lower communication costs (McCloskey and Klamer, 1995), and simultaneously increase the likelihood that decisions are made by people with a similar mindset.

\footnotetext{
${ }^{4}$ A recent exception is Guiso et al. (2009), where nevertheless the focus of analysis is on the determinants of bilateral trust among pairs of countries. In the regional science field, the inclusion of multiple concepts of non-geographical proximity in the empirical analysis of knowledge creation and diffusion processes includes, among others, Maggioni et al. (2007) and Marrocu et al. (2011).
} 
Agents of regions with a similar technological specialization (i.e. those enjoying technological proximity) may, in turn, find it easier to access potential technological spillovers, by means of reverse engineering technologically-compatible products (Padilla-Pérez, 2008). Technological proximity may therefore foster knowledge diffusion by increasing the probability of the cross-fertilization of ideas.

Cognitive proximity is instead based on a relatively new concept, viz. that of cognitive capital. There have been two convincing definitions of this new concept. On the one hand, Boschma and co-authors extend the notion of related variety to cognitive proximity, i.e. they posit that industries and regions must be cognitively neither too close, nor too distant, in order to trigger mutual learning processes: "Some degree of cognitive proximity between two sectors ensures effective communication and common understanding, and some degree of cognitive distance is needed to avoid cognitive lock-in" (Boschma et al., 2012: p. 243). On the other hand, cognitive capital has also been recently defined as “(...) mental processes and resulting ideas, reinforced by culture and ideology, specifically norms, values, attitudes, and beliefs that contribute cooperative behavior and mutually beneficial collective action" (Uphoff, 1999, p. 218). This definition breaks down the concept of social capital into two main axes, viz. structural and cognitive social capital. Proximate regions in terms of their (mostly scientific and industrial) culture and ideology (i.e. in their cognitive social capital) are expected to share a common communication code, thereby fostering knowledge transfer. ${ }^{5}$ In our view, this definition, based on the notion of cognition, is fully compatible with that of Boschma and co-authors.

Relational proximity is defined as the capability of regions to learn through cooperation. This concept has been thoroughly examined by the GREMI school, although its validity has seldom been empirically verified. Agents (and, in the present case, regions) being relationally proximate take part in processes of collective learning (Camagni, 1991; Perrin, 1995). In this paper, relational proximity is proxied by the intensity of scientific relations between pairs of regions (i.e. by the set of short- and long-distance networks that enable the easier flow of knowledge across space).

In this paper, one major aspect of novelty concerns the way the usual approach to KS is carried out. In fact, instead of verifying the channels through which regions can benefit from knowledge generated outside, we verify through which non-geographical channels regions can prevent the emergence of OKSs.

This paper argues that none of these forms of proximity alone is sufficient to fully account for all channels of knowledge diffusion. However, each of these proximities is based upon a convincing theoretical explanation of the mechanisms and channels of knowledge diffusion that they represent. Therefore, in Sections 3-6 we test empirically the validity of each of these forms of proximity as real channels of knowledge diffusion.

\section{Methodology, research question and estimation model}

The first research task was to define different types of proximity. Next, it was necessary to identify a measure for each type of proximity and to employ it within the framework set up in Caragliu and Nijkamp

\footnotetext{
${ }^{5}$ This concept has been operationalized in Caragliu and Nijkamp (2013).
} 
(2012). A new measure of OKSs will be defined here and employed in order to analyse its determinants in a regional setting. In this subsection, we briefly introduce this econometric transformation, based simply on geographical space, and move a step forward by asking the following research question:

\section{RQ. Which non-spatial channels transmit KSs?}

In other words, we employ the econometric framework presented below in order to test the change in the estimated parameters induced by applying the transformation with the use of different proximity matrices other than the simple one based on just geographical space.

Suppose the regional stock of knowledge is produced according to a linear KPF as:

$Y=X \beta+\varepsilon$,

where matrix $X$ encompasses all relevant determinants of regional knowledge production, and $Y$ represents a measure of knowledge. Here, knowledge is measured by Total Factor Productivity (henceforth, TFP). ${ }^{6}$

Regional TFP is typically affected by spatial autocorrelation, i.e. its values are distance-sensitive and tend to be clustered in space. In this case, spatial econometrics clarifies how linear techniques would yield biased parameter estimates. In fact, eq. (1) can be rewritten to take into account spatial autocorrelation patterns as follows:

$Y=\rho W Y+X \beta+\varepsilon$

where $\mathrm{W}$ is a (spatial) weight matrix, and $\rho$ is the spatial autocorrelation coefficient. The latter displays a behaviour similar to that of the equivalent parameter in time series modes. In particular, a value of $\rho$ bigger than 1 in absolute terms implies that spatial correlation becomes larger, the longer the distance.

Eq. (2) cannot be estimated directly. In order to solve this issue, the terms must be rearranged by bringing the $\rho W Y$ term to the left-hand side, isolating $Y$ and pre-multiplying the matrix $(I-\rho W)^{-1}$ to the $X$ matrix and the $\varepsilon$ vector. The $(I-\rho W)$ matrix is obtained as follows:

$B=(I-\rho W)=\left(\begin{array}{cccc}1 & 0 & \ldots & 0 \\ 0 & 1 & \ldots & 0 \\ 0 & \ldots & \ldots & 0 \\ 0 & 0 & \ldots & 1\end{array}\right)-\hat{\rho}\left(\begin{array}{cccc}w_{11} & w_{12} & \ldots & w_{1 n} \\ w_{21} & w_{22} & \ldots & w_{2 n} \\ \ldots & \ldots & \ldots & \ldots \\ w_{n 1} & \ldots & \ldots & w_{n n}\end{array}\right)$,

where $B$ is the Greek upper-case letter $B$, from the word meaning "weight"; $\hat{\rho}$ is the (estimated) autocorrelation parameter; and $w_{i j}$ represents distance values between analysed regions. Eq. (3) shows that the result of this calculation is an $(n \times n)$ matrix. This matrix, after being inverted, transforms each variable in the $X$ matrix into its contribution, to and from each region, to the dependent variable. In other words, it can be interpreted as an input-output matrix, where each element shows the weight to be assigned to each

\footnotetext{
${ }^{6}$ This means that we calculate the residuals of a production function of the form $Y=A K^{\alpha} L^{1-\alpha}$. The stock of capital is calculated with the perpetual inventory method, assuming a yearly constant depreciation rate of 2.5 per cent, on the basis of EUROSTAT's Gross Fixed Capital Formation series, with 1990 as the base year.
} 
observation in the vectors stacked in the $X$ matrix in order to obtain inward and outward flows of these elements to the region observed. Finally, by pre-multiplying matrix $B$ by the TFP vector we obtain our measure of OKSs. Such a measure represents the balance of positive and negative absolute knowledge flows across regions.

The first step to apply our transformation entails, therefore, the estimation of the KPF. In this paper we follow recent applied studies on the main determinants of productivity; in particular, the variables included in the instrumental estimates of the KPF are chosen according to the sample employed in Loko and Diouf (2009) and Eichler et al. (2005). Our KPF takes therefore the form:

$T F P_{r, t}=\alpha^{*} H C_{r, t}+\beta^{*} R \& D_{r, t}+\gamma^{*} \Delta A C C E S S_{r, t}+\delta^{*} F D I_{r, t}+\zeta * I N S T_{i, t}+\varepsilon_{r, t}$,

where indices $r, i$ and $t$ indicate the region, country and time, respectively. Regional TFP depends, therefore, not only on a set of regional determinants (the level of human capital, the intensity of R\&D, the level of accessibility, and the intensity of FDIs), but also on country-level institutional and context elements, in this paper captured by country fixed effects. Such country-varying factors include: the level of taxes; political institutions; the quality and type of the schooling system; the inflation rate ${ }^{7}$ government size; and national industrial regulation. The results of estimating the a-spatial KPF are shown in the next Section.

Once our transformation has been employed, we obtain $n$ measures of potential OKSs, one for each weight matrix adopted; the OKS measure takes on positive or negative values if, respectively, outward or inward potential knowledge flows prevail in the region. ${ }^{8}$ These measures present markedly different features and behaviour; the maps of all five indicators are shown in the Technical Appendix of this paper.

Finally, and following our previous work on this topic, we propose the following implicit form equation for OKSs:

Outward spillovers $_{i}=f\left(R \& D_{i}\right.$, AbsorptiveCapacity $_{i}$, AbsorptiveCapacity $_{i}{ }^{*}$ AbsorptiveCapacity $_{j}$, AbsorptiveCapacity $)^{\text {, }}$

where region $i$ is the region under consideration; and regions $j$, with $j \neq i$, are all other regions. A major departure from previous work lies in a more careful definition of absorptive capacity, which is measured here, following Cohen and Levinthal (1990), as the cumulated stock of patents granted by the European Patent Office between 1999 and $2005 .^{9}$

\footnotetext{
${ }^{7}$ Regionally-varying price levels are not available.

${ }^{8}$ Interestingly, the measure of knowledge spillovers calculated here is based on the fact that we focus our attention on outward knowledge spillovers. This is reflected in the choice of row-standardized proximity matrices. Were the opposite assumed, the use of column standardized matrices would be recommended instead (Ponds et al., 2010). We thank an anonymous referee for pointing at this issue.

${ }^{9}$ The stock of cumulated knowledge, viz. the measure of regional absorptive capacity, is calculated with a perpetual inventory method. The first year's stock is calculated as the total number of patents granted in 1990 discounted by 0.05 (an average yearly discount rate $\delta$ of 2.5 per cent, plus an assumed labour productivity growth rate of 2.5 per cent). Subsequent years are then built, defining $K(t)$ which is the stock of knowledge at time $\mathrm{t}$, as $K(t)=K(t-1) *(1-\delta)+\Delta$ $(K(t)$. The resulting time span covers the period 1999-2005.
} 
In our conceptual framework, absorptive capacity takes on a double nature. On the one hand, local R\&D expenditure fosters the generation of OKSs: this implies we expect a positive sign for simply the intensity of R\&D within each region, as local R\&D increases the likelihood of an external leakage of new knowledge (i.e. a process of inter-regional knowledge diffusion). On the other hand, long-run investment in $R \& D$, leading to the accumulation of technical knowledge embedded in the stock of patents, increases the local capability to understand, decode, and fully exploit newly produced knowledge. As such, we may expect eq. (5) to meet the following plausible expectations:

- A positive sign for local $\mathbf{R} \& \mathbf{D}$ intensity. More expenditure in innovation activities in a region provides the rationale for the generation of outward KSs;

- A negative sign for the local absorptive capacity term. Even assuming the external world has no absorptive capacity at all (i.e. the 'pull' effect equals zero), a higher stock of previously accumulated knowledge within the region fosters its chances to retain internally the positive fallout of $R \& D$ activity.

- A negative sign for the interaction term. Cognitive skills in understanding, decoding, and exploiting locally-produced knowledge, both in the knowledge-generating region (henceforth, KGR) as well as in regions which are spatially, technologically, socially, relationally, and cognitively proximate, should ultimately hamper outward KSs. This result is also in line with the original Cohen and Levinthal framework. In other words, only when a region has a strong absorptive capacity, and is surrounded by regions similarly high in absorptive capacity, is it able to retain the positive effects of local innovation within its boundaries.

- A positive sign for surrounding areas' absorptive capacity. In a way, this last expectation is the reverse of the first point: when neighbouring regions own large stocks of knowledge, they tend to exert a pull effect on locally produced knowledge. Their socio-economic soil is more fertile and ready to reap the positive effects of externally produced knowledge, through commuting patterns, input output mechanisms, and formal and informal exchange of new ideas. Finally, this last sign is expected to be positive for one more reason. KSs happen through several different channels, one of which is trade: through reverse engineering, firms can acquire technology embedded in traded goods (Padilla-Pérez 2008). More knowledge accumulated in external regions implies therefore a pull effect for the locally-produced knowledge.

The positive sign expected from the local R\&D investment can be read as a 'push' effect; in fact, higher R\&D investments are expected to increase the likelihood of locally-generated knowledge to spill over to surrounding areas. The negative sign for the local absorptive capacity and the interaction term can be read as a 'containment' effect. Ceteris paribus, regions with stronger efforts in knowledge production can withhold part of the (likely) knowledge leakages when other regions are similarly endowed with absorptive capacity, viz. their capability to understand, efficiently adopt, and economically exploit the knowledge locally produced. The positive sign for surrounding areas' absorptive capacity can be finally interpreted as a 'pull' 
effect: the existence of other regions with a high absorptive capacity exerts a competitive pressure on the positive leakages from local knowledge production. Firms outside each region continuously look for new sources of potentially revenue- and productivity-enhancing knowledge; as such, the higher the external world's absorptive capacity, the higher the likelihood that OKSs will take place.

\section{The data set}

In order to test eq. (5), we collected a new database covering the years 1999-2005, with EUROSTAT data on gross expenditure in $\mathrm{R} \& \mathrm{D}$, regional population, value added (in constant 2000 prices), labour force, and capital stock. $^{10}$

A novel characteristic of this paper is the aim to encompass in one single study a comprehensive classification of the various types of proximities in the analysis of KSs. We define five types of proximity, and use each proximity matrix to construct the measure of OKS described in the previous section. ${ }^{11} \mathrm{~A}$ first attempt to capture the role of different types of proximity in the generation of KSs among European regions is carried out in Basile et al. (2012). A more recent contribution (Capello and Caragliu, 2012) moves a step forward in this direction by building indicators for different forms of non-geographical proximity; these indicators are then used to verify the impact of various proximities on the intensity of scientific cooperation. ${ }^{12}$ We follow this last approach, and identify the following indicators of proximity between pairs of regions (see Table 2):

Table 2. Measuring different types of proximity

\begin{tabular}{cc}
\hline \multicolumn{1}{c}{ Proximity } & Indicator \\
\hline \hline Geographical proximity & Geographical distance between pairs of centroids. \\
\hline Relational proximity & $\operatorname{rel}_{i j}=$ copartFP $_{i j}$ \\
\hline Social proximity & $\operatorname{soc}_{i j}=\left|\sum_{q=1}^{Q}\left(x_{q i}-x_{q j}\right)^{2}\right| / \sum_{q=1}^{Q}\left(x_{q i}+x_{q j}\right)$ \\
\hline Technological proximity & $\operatorname{tech}_{i j}=\left|\sum_{s=1}^{m}\left(x_{s i}-x_{s j}\right)^{2}\right| / \sum_{s=1}^{m}\left(x_{s i}+x_{s j}\right)$ \\
\hline Cognitive proximity & $\operatorname{cog}_{i j}=\sum_{k=1}^{7} x_{i, k}^{2} x_{j, k}^{2} * \sum_{h=1}^{30} x_{i, h}^{2} x_{j, h}^{2}$ \\
\hline
\end{tabular}

For geographical proximity, for each pair of regions we calculate the traditional distance in arcminutes between pairs of centroids.

\footnotetext{
${ }^{10}$ The stock of capital is calculated with the perpetual inventory method, on the basis of EUROSTAT's gross fixed capital formation time series. The base year for all calculations is 1995 , while we assume an yearly depreciation rate of 2.5 per cent.

${ }^{11}$ The five maps representing the measures of inward and outward flows of knowledge used as the dependent variable in our regressions are shown in Figures A2-A6 in Section 5 of the Technical Appendix.

12 In turn, the present work has been conceived within the framework of the ESPON KIT project (http://www.espon.eu/main/Menu Projects/Menu AppliedResearch/kit.html).
} 
For relational proximity, following Maggioni and Uberti (2009) and Basile et al. (2012), we calculate coparticipation between pairs of regions in the joint Framework Programme 5 projects. ${ }^{13}$ This is also in line with a rich literature dealing with R\&D collaboration (e.g. Scherngell and Barber, 2009, 2011; AutantBernard et al., 2007). ${ }^{14}$

For technological proximity, we calculate the Euclidean average distance between regions in terms of regional specialization (in terms of location quotients in NACE 2 manufacturing sectors).

For social proximity, we calculate the Euclidean average distance between regions in terms of social capital. The wealth of regional social capital is measured using a principal component analysis (PCA) on four social capital axes, as traditionally defined in previous studies on this topic (see, for instance, Putnam, 2000). ${ }^{15}$

Finally, the last proximity measure calculated deserves specific attention. Cognitive proximity is captured, by analogy with the literature on related variety, as the variety of patenting activity within 3-digit classes, multiplied by the similarity within 2-digit classes. Nevertheless, unlike previous work by Broekel and Boschma (2012), the notion of related variety is extended to the cross-regional case. In particular, we posit that regions can reap maximum benefits from other knowledge-generating regions when they are neither too far, nor too close (from an industrial perspective). ${ }^{16}$

Overall, our data set covers a set of 264 European NUTS2 regions, for the period 1999-2005. This yields a total of 1848 observations. ${ }^{17}$

The proximity measures built here do indeed capture different ways in which economic interactions are structured over space. Table 3 shows the Pearson's correlation indices calculated between all pairs of proximity measures. Values range from -0.18 to 0.14 ; indeed, proximity measures show a relatively low degree of mutual correlation, which supports the idea behind the present paper.

Table 3. Correlation matrix among proximity matrices

\begin{tabular}{l|ccccc}
\hline & Relational & Cognitive & Technological & Social & Geographical \\
\hline Relational & 1.00 & -0.08 & -0.09 & -0.05 & 0.07 \\
\hline Cognitive & -0.08 & 1.00 & 0.12 & 0.11 & -0.02 \\
\hline Technological & -0.09 & 0.12 & 1.00 & 0.14 & -0.08 \\
\hline Social & -0.05 & 0.11 & 0.14 & 1.00 & -0.18 \\
\hline
\end{tabular}

\footnotetext{
${ }^{13}$ European FPs are aimed at fostering scientific research in the European Union. The $5^{\text {th }}$ wave of FPs covered the period 1998-2002. We chose FP5 in order to cover the highest number of regions. The FP5 data set has been collected in European Commission (2005). A more recent wave, the $6^{\text {th }}$, is also available, but with no geo-referentiation, which is necessary to calculate inter-regional relational proximity.

${ }^{14}$ The use of FP5 co-participation data represents a biased measure of learning through cooperation, since typically the spatial distribution of universities is uneven across space. Regions lacking prestigious or internationally-active universities may in fact be characterized by the presence of other institutions capable of cooperating internationally.

${ }^{15}$ The details on such calculations are given in Section 2 of the Technical Appendix.

${ }^{16}$ More details of the calculations needed to obtain the cognitive proximity matrix are available in Section 4 of the Technical Appendix of the paper.

${ }^{17}$ Further details on the various proximity matrices are given in Section 1 of the Technical Appendix.
} 


\begin{tabular}{l|lllll}
\hline Geographical & 0.07 & -0.02 & -0.08 & -0.18 & 1.00 \\
\hline
\end{tabular}

Source: Authors' calculations.

\section{Estimation results}

This section aims at highlighting the relevance of different channels of knowledge diffusion across European regions. Eq. (5) can be rewritten in linear form as:

$$
O K S_{r, t}=\alpha+\beta A C_{r, t}+\gamma A C_{r, t} * A C_{j, t}+\delta A C_{j, t}+\varepsilon_{r, t} .
$$

Our previous work on a similar equation suggested that absorptive capacity in the originating region is expected to reduce OKSs, which are actually positively correlated with absorptive capacity in neighbouring regions and the intensity of local R\&D. In this section, we first briefly present the results of estimating the aspatial KPF, which is instrumental to calculating our measures of OKSs (Section 5.1); and, next, we present the main findings of re-estimating model (6), with the use of the proximity matrices defined in Section 4.

\subsection{The knowledge production function}

The results of estimating eq. (4) are shown in Table 4. Most parameter estimates yield meaningful results, while the significance of country fixed effects suggests the high relevance of country characteristics in the production of local knowledge. ${ }^{18}$

Table 4. Estimation results for the Knowledge Production Function (eq. 1)

\begin{tabular}{lcccc}
\hline \multicolumn{5}{c}{ Dep. variable: regional Total Factor Productivity in 2007} \\
Model & $(1)$ & $(2)$ & $(3)$ & $(4)$ \\
\hline \hline Constant term & $-0.20^{* * *}$ & $-0.20^{* * *}$ & $-0.22^{* * *}$ & -0.08 \\
Human capital (\% labour force with ISCED 5 & $1.06^{* * *}$ & $1.04^{* * *}$ & $1.06^{* * *}$ & $0.97^{* * *}$ \\
and 6 education) & $(0.30)$ & $(0.28)$ & $(0.28)$ & $(0.27)$ \\
R\&D intensity (Gross Expenditure in R\&D per & - & $0.05^{* *}$ & $0.05^{* *}$ & $0.04^{* *}$ \\
1,000 population) & & $(0.02)$ & $(0.02)$ & $(0.02)$ \\
Growth of multimodal accessibility & - & - & $0.01^{* *}$ & $0.01^{* *}$ \\
& & & $(0.00)$ & $(0.00)$ \\
Inward Foreign Direct Investments & - & - & - & $0.02^{*}$ \\
& & & & $(0.01)$ \\
Country Fixed Effects & & & & \\
Robust standard errors & Yes & Yes & Yes & Yes \\
& Yes & Yes & Yes & Yes
\end{tabular}

${ }^{18}$ These estimates can be compared with those based on Spatial Auto Regressive (SAR) models, which are suggested on the basis of the inspection of the usual battery of tests discriminating between SAR and Spatial Error Models (SEM). In this case, the Wald test of $\rho=0$ is rejected at the $95 \%$ confidence level, with a $\chi^{2}(1)=4.806(0.028)$, and the corresponding likelihood ratio test of $\rho=0$ is also rejected at the $95 \%$ confidence level, with a $\chi^{2}(1)=5.240(0.022)$. The SEM model presents the opposite results. The Wald test of $\lambda=0$ is not rejected at any confidence level, with a $\chi^{2}(1)=0.004(0.949)$, and the corresponding likelihood ratio test of $\lambda=0$ is also never rejected at any confidence level, with a $\chi^{2}(1)=0.004(0.949)$. Hence, it is clear that the SAR model should be preferred. 
Joint $\mathrm{F}$ test $\quad 19.34 * * * 19.63 * * * 13.10 * * * 13.67 * * *$

$\begin{array}{lllll}\text { Number of observations } & 264 & 264 & 264 & 259\end{array}$

Note. *: 90\% significance level; **: 95\% significance level; ***: 99\% significance level. Standard errors in parentheses.

A second crucial step in calculating our measure is the assessment of spatial trends in the KPF. In this paper, we move a step beyond our previous research, and identify spatial trends using Moran's $I$ statistics calculated on the basis of the five typologies of proximity described in Section 2. The results of this process are shown in Table 5, along with the estimated parameter of the spatially-augmented KPF.

Table 5. Moran's I statistics and values of the estimated $\rho$ 's, according to different notions of proximity

\begin{tabular}{lcc}
\hline $\begin{array}{l}\text { Type of } \\
\text { proximity }\end{array}$ & $\begin{array}{c}\text { Global Moran's I } \\
\text { of regional TFP }\end{array}$ & $\begin{array}{c}\text { Spatial autocorrelation } \\
\text { coefficient of the KPF }\end{array}$ \\
\hline \hline Physical & $0.07 * * *$ & $0.51 * * *$ \\
Social & $-0.02 * * *$ & $-2.45^{* * *}$ \\
Relational & $0.16^{* * *}$ & $0.86 * * *$ \\
Technological & $-0.02 * * *$ & -1.19 \\
Cognitive & -0.01 & $-3.35 * *$ \\
\hline
\end{tabular}

The values of the $\rho s$ shown in Table 6 are employed to calculate the dependent variables of the main estimates.

\subsection{Main estimations}

Section 5.2 presents the results of estimating the main model (eq. 6), with OLS estimates running from column 1 to column 5 (Table 6).

Table 6. Estimation results for the main model (eq. 6)

\begin{tabular}{l|ccccc}
\hline Dep. variable: outward knowledge spillovers & \multicolumn{5}{c}{ OLS estimates } \\
\hline Model & $(1)$ & $(2)$ & $(3)$ & $(4)$ & $(5)$ \\
Proximity matrix used & Geographical & Relational & Social & Technological & Cognitive \\
\hline Constant term & $-0.10^{* * *}$ & $0.54 * * *$ & -0.03 & 0.01 & -0.01 \\
& $(0.04)$ & $(0.05)$ & $(0.05)$ & $(0.05)$ & $(0.06)$ \\
R\&D intensity & $0.01 * * *$ & 0.01 & 0.01 & 0.01 & $0.02^{*}$ \\
& $(0.00)$ & $(0.01)$ & $(0.01)$ & $(0.01)$ & $(0.01)$ \\
Local absorptive capacity & $-0.01 * * *$ & -0.01 & -0.01 & -0.02 & -0.01 \\
& $(0.00)$ & $(0.00)$ & $(0.00)$ & $(0.02)$ & $(0.00)$ \\
Local absorptive capacity*lagged absorptive & $-0.29 * *$ & $-0.17 * * *$ & $-0.18^{* * *}$ & $-0.18^{* * *}$ & $-0.23^{* * *}$ \\
capacity & $(0.08)$ & $(0.04)$ & $(0.04)$ & $(0.04)$ & $(0.05)$ \\
& $2.61 * * *$ & 0.66 & 1.59 & $-0.06 * * *$ & $0.05^{*}$ \\
Lagged absoprtive capacity & $(0.52)$ & $(0.64)$ & $(1.35)$ & $(0.02)$ & $(0.03)$ \\
Country fixed effects & Yes & Yes & Yes & Yes & Yes \\
Robust standard errors & Yes & Yes & Yes & Yes & Yes
\end{tabular}




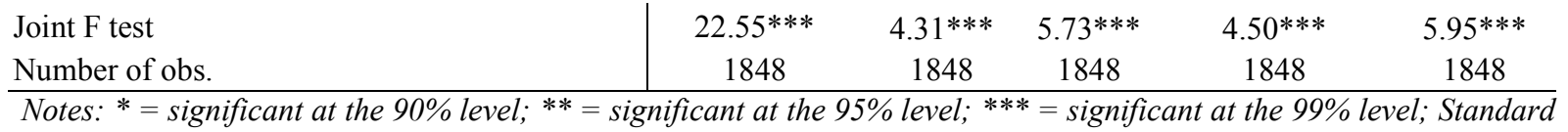
errors are shown in brackets.

Models 1-5 present OLS estimates of the main model, which vary because of the rotation of different definitions of proximity that enter the calculation of both the dependent variable and the lagged absorptive capacity. Although these estimates use the same econometric transformation first proposed in Caragliu and Nijkamp (2012), the equation estimated and the data set used present minor differences; this being the case, this column cannot be compared with the main estimates in the original contribution.

For all specifications, the main findings on the role of local R\&D as a net generator of OKSs are confirmed, although the significance associated with the parameter for the "push" effect is marginally below the 10 per cent level of confidence for most proximity definitions of OKSs.

The containment effect (i.e. the interaction term local - push effect - and lagged absorptive capacity - pull effect) presents unequivocal findings. With respect to geographical proximity-based estimates, this empirical test yields a powerful confirmation that less OKSs are generated in the presence of a higher local absorptive capacity, even when other regions enjoy high levels of absorptive capacity, as such regions are spatially remote, or relationally, socially, technologically, and cognitively distant. This implies that not only geography, but also technology, cognitive maps, social values and networks represent spaces where knowledge travels; therefore, as distance using such measures increases, knowledge travels less easily. ${ }^{19}$

In addition, this result also suggests that local absorptive capacity needs to be matched by external absorptive capacity in order to maximize the returns to local knowledge generation, and retain its positive effects internally. This result presents some striking similarities with the literature on 'poverty traps' (Azariadis, 1996); in fact, the need for a simultaneous wealth of local and lagged absorptive capacity implies that even relevant local investments in absorptive capacity may fail to maximize the returns to local $\mathrm{R} \& \mathrm{D}$, if other regions do not follow the same path. This result, in turn, suggests the presence of a path of absorptive capacity lock-in: regions which are surrounded by areas with low absorptive capacity, but insufficiently capable of absorbing knowledge, may fail to maximize the returns from their own R\&D investment.

Finally, the pull effect, viz. the parameter associated with the lagged values of absorptive capacity, presents an unexpected result that seems to be less in line with the original, geographically-based, framework. The original results suggested that knowledge may travel more easily across regions both characterized by high levels of previously produced knowledge, and would in particular be attracted by regions surrounding the KGR with a high absorptive capacity; this result is confirmed for geographical and cognitive proximity. Our

\footnotetext{
${ }^{19}$ The negative sign of the interaction term can be interpreted as evidence of "locational shadowing" (Maggioni, 2002). We thank an anonymous referee for this point.
} 
results show instead that regions which are technologically compatible with the KGR tend to foster actual knowledge acquisition in the KGR. ${ }^{20}$

A highly significant joint $\mathrm{F}$ test for all the estimates provides evidence of the strength of the empirical test. This point confirms the absence of spatial autocorrelation of the OKS measures calculated with the methods described above: proximity effects in fact have been removed from the original knowledge (TFP) measure.

\section{Graphical analysis}

The parameter estimates associated with the most important parameter in our estimates, viz. the intensity of the interaction term, which shows the so-called 'containment effect', are plotted in Figure 2. This figure shows that geographical distance does indeed play a major role in explaining distance-decay functions, although technological and cognitive proximity still provide a major explanation of the ease with which regions are capable of retaining the positive effects of their own R\&D activity internally.

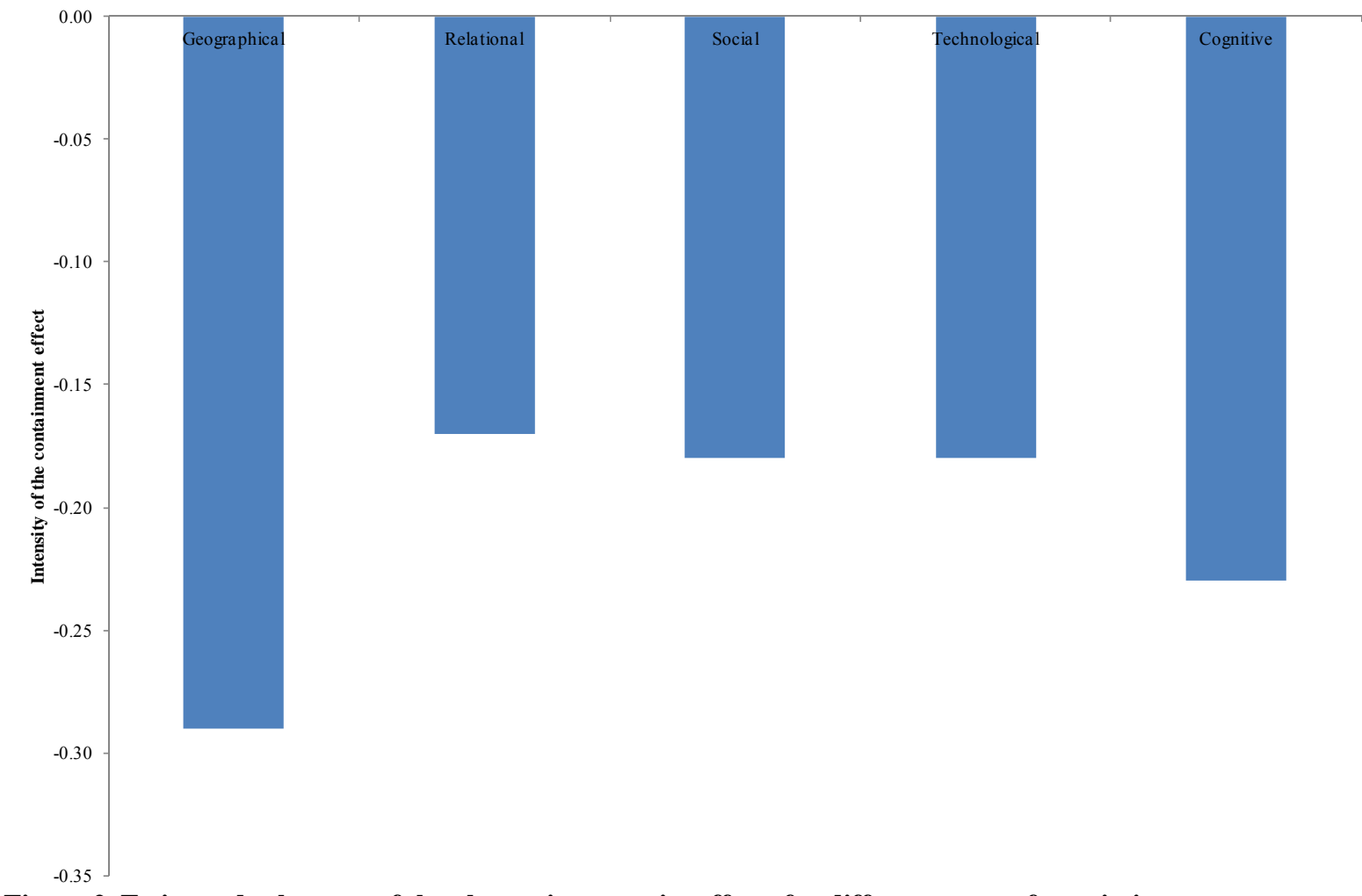

Figure 2. Estimated relevance of the absorptive capacity effects for different types of proximity Source: Authors' calculations (see Table 6).

However, the relative role of local absorptive capacity as the lagged value changes also depends on the absolute levels of both local, as well as lagged, absorptive capacity. A graphical interpretation is provided in Figure 3 (3.a-3.e), where, for each definition of proximity, we plot the marginal effects of local absorptive

\footnotetext{
${ }^{20}$ This set of estimates presents possible problems of endogeneity which may be difficult to rule out with full confidence. An indication of the resilience of the estimates comes from the relative stability of the most important parameter, viz. the interaction term, throughout all the estimates. Further evidence may come from an instrumentation of the main estimates, which would, however, need credible instruments (possibly, time-lagged variables for each of the proximity measures here adopted). In Caragliu and Nijkamp (2012), this is done for the geographical proximity-based regressions.
} 


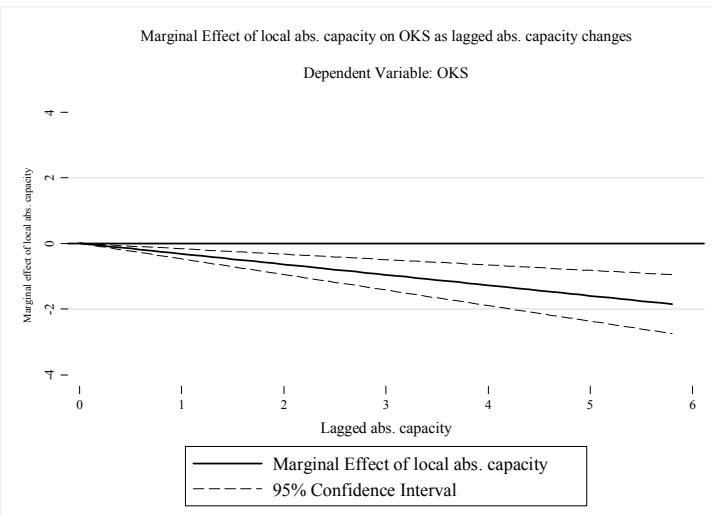

Figure 3.a: Marginal effects of lagged absorptive capacity on the impact of local absorptive capacity on OKSs, geographical matrix.

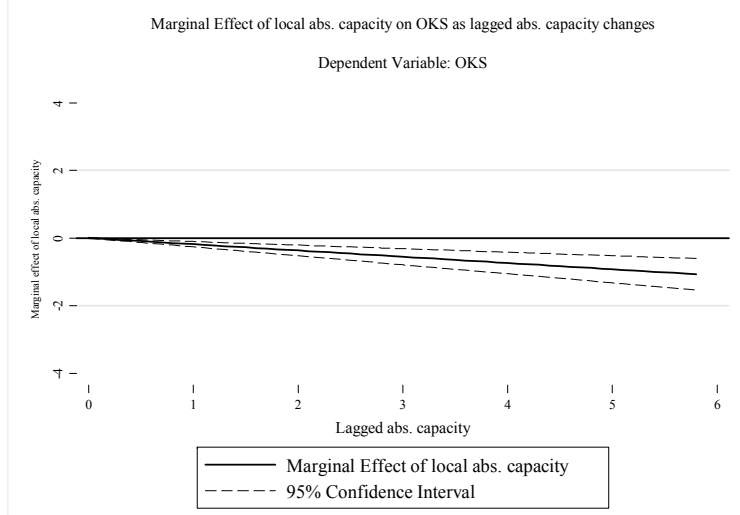

Figure 3.d: Marginal effects of lagged absorptive capacity on the impact of local absorptive capacity on OKSs, technological matrix.

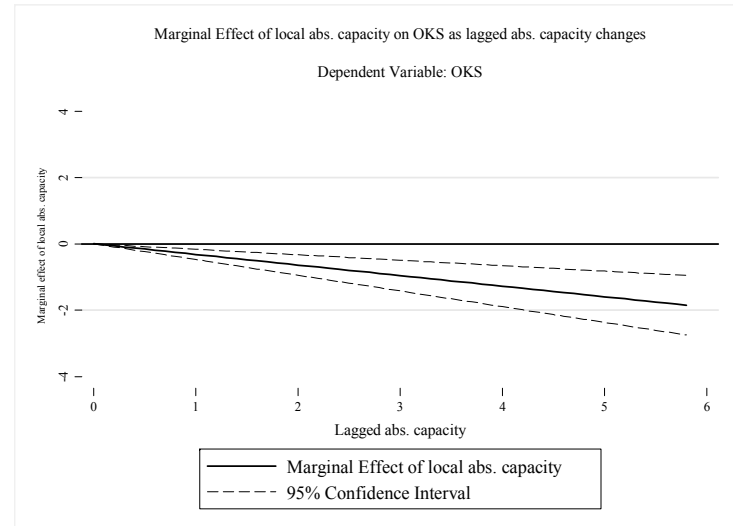

Figure 3.b: Marginal effects of lagged absorptive capacity on the impact of local absorptive capacity on OKSs, relational matrix.

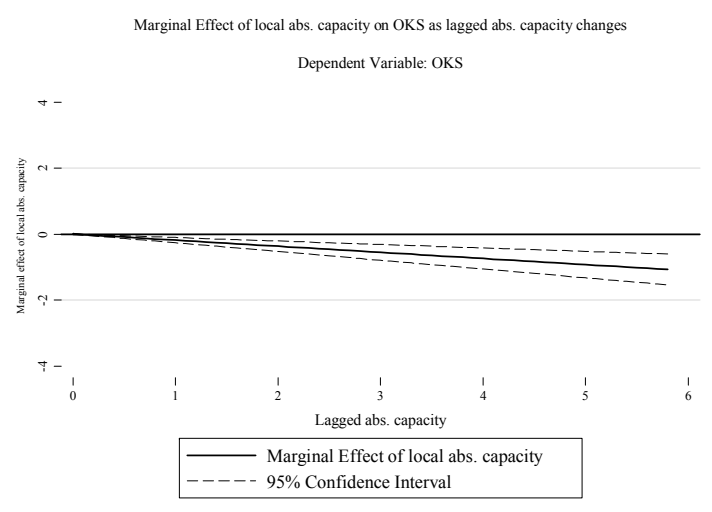

Figure 3.e: Marginal effects of lagged absorptive capacity on the impact of local absorptive capacity on OKSs, cognitive matrix.

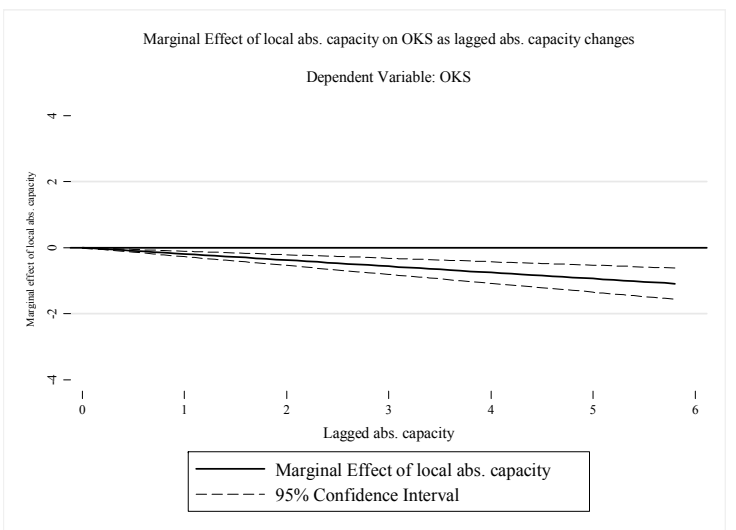

Figure 3.c: Marginal effects of lagged absorptive capacity on the impact of local absorptive capacity on OKSs, social matrix.

\section{Figure 3. Marginal effects of local absorptive capacity on OKSs as lagged absorptive capacity changes}

Source: Authors' calculations. 
capacity as the lagged value of absorptive capacity changes. Along with the impacts of local absorptive capacity, confidence intervals calculated at the $95 \%$ per cent level are also shown. In this set of figures, the finding is still valid that higher distances from other regions (in terms of geography, but also with respect to social values, scientific relations, technological paradigm, and cognitive maps): ceteris paribus, and in particular given similar levels of knowledge-generation capabilities, regions reduce OKS as they increase their distance from other potential competitors.

Figure 3 above shows that across all five specifications, the absolute effect of local absorptive capacity on the generation of OKSs is always negative, although when the lagged absorptive capacity parameter takes on very low levels this effect is very close to zero. This negative effect increases in magnitude as the level of lagged absorptive capacity increases. This implies that local absorptive capacity does not suffice per se to prevent OKSs. Isolated investment efforts in the accumulation of absorptive capacity may not suffice to maximize the local returns to, and exploitation of, R\&D. Hence, this empirical contribution raises the issue of "absorptive capacity traps", which would represent a major challenge for future R\&D policies.

Since the lagged absorptive capacity measure is calculated using the various proximity matrices as filters, these results suggest that regions may also prevent OKS by locking their knowledge set away from potential competitors, by:

- Specializing in technologies that are not compatible with the average technological paradigm;

- Enhancing differences in their social capital from the social values of other regions;

- Avoiding thick and wide networks of scientific cooperation;

- Fostering the emergence of cognitive maps orthogonal to those of potential competing regions.

These results suggest that space, conceived in ways richer that just geography, may still represent a constraint to the diffusion of knowledge. This, from the perspective of the KGR, may represent a fundamental asset for preventing the loss of positive KSs to the outside world.

\section{Conclusions and policy implications}

In this paper we have adopted the analytical framework developed in Caragliu and Nijkamp (2012) and employed in finer spatial detail in Caragliu and Del Bo (2011) in order to provide additional insight into the nature of OKSs, and the channels through which they are expected to travel. To this end, we presented a critical review of the traditional literature on different types of proximity, and provided an operational classification of these studies, which was employed to define five main types of proximities (geographical, relational, social, technological, and cognitive) capable of explaining KSs.

The empirical results show that the main findings of our previous studies hold. However, some major differences in the magnitude and significance of the estimated parameters suggest that knowledge may travel with more or less impedance, according to the channel through which it moves. In particular, along with the traditional findings on geographical proximity, cognitive proximity (measured as the inter-regional related 
variety in terms of patenting profiles of the regions) provides the highest explanatory power among all the typologies employed in this paper.

In addition, the results clearly show that local absorptive capacity enhances the likelihood of KGRs being able to maximize the local returns to R\&D only when coupled with a similarly high level of absorptive capacity in other regions. However, space - conceived of as technological, cognitive, social, and relational in nature - still represents a major hurdle for knowledge diffusion. The higher geographical, technological, cognitive, social, and relational distance are, the lower OKS are expected to be. This points towards the emergence of 'absorptive capacity clubs', while KGRs which aim to accumulate absorptive capacity, i.e. to invest over long time spans to accumulate local knowledge, may find it impossible to reap the benefits of such investment, in the absence of surrounding regions with similar high levels of absorptive capacity.

This possible trap should be further investigated: one future research direction could be the analysis of the microfoundations of cooperation networks among regions, a topic which has recently received much scientific attention (see, for instance, Autant-Bernard et al., 2007, and Scherngell and Barber, 2009; 2011).

One major implication of this last point is the relevance of supra-regional coordination of policies. According to our empirical findings, regions must still invest in local R\&D accumulation in order to generate new knowledge. However, in the absence of similar efforts in other areas, such investment may provide suboptimal outcomes. On the other hand, an alternative strategy for regions which are aiming to prevent the generation of OKSs is to lock-in in technological paradigms and social capital orthogonal to those of other regions, or to restrict connectedness in scientific relations, or to limit their cognitive complementarity with other regions.

Furthermore, our results create a new agenda for empirical studies on the topic of KSs. Omitting the use of alternative measures of proximity may in fact blur the image that empirical economists obtain of the flows of knowledge across space. This in turn would inevitably lead to partially wrong policy conclusions.

One additional research topic in the same line of research as ours would imply abandoning the use of a general knowledge measure, such as TFP, as the basis for our KS measure, and the choice of several different knowledge measures. Different types of knowledge may indeed travel through different channels, and our empirical approach may provide a first estimate of the relative importance of such diverse laws governing knowledge flows.

Because of the interest of both academics and policy makers in the topic of KSs, and the rich nature of the spatial characteristics captured in the five types of proximity summarized here, further work on each of the four alternative definitions of proximity, apart from geographical proximity, would benefit our understanding of the mechanics of knowledge creation, diffusion, and absorption.

Empirically, this implies the creation of a long-term database of relational, social, technological and cognitive characteristics, linking pairs of regions and allowing the assessment of mutual knowledge flows. 
Moreover, a deeper insight into the different types of proximity identified here may provide a better understanding of the ensuing empirical results.

Finally, a relevant implication of our results lies in the crucial role of region-specific social, technological, cognitive and relational characteristics in shaping sound place-based policies (Barca, 2009; European Commission, 2011); without properly accounting for such properties, and for the interaction between them, any smart policy on regions in Europe is inevitably bound to fail.

\section{References}

Acs, Z., Audretsch, D. and Feldman, M. P. (1994). "R\&D spillovers and recipient firm size", Review of Economics and Statistics, 76 (2): 336-340.

Agrawal, A., Cockburn, I. and McHale, J. (2006). "Gone but not forgotten: labor flows, knowledge spillovers and enduring social capital", Journal of Economic Geography, 6 (5): 571-591.

Autant-Bernard, C., Billand, P., Frachisse, D. and Massard, N. (2007). "Social distance versus spatial distance in R\&D cooperation: empirical evidence from European collaboration choices in micro and nanotechnologies", Papers in Regional Science, 86 (3): 495-519.

Aydalot, P. (ed) (1986). "Milieux innovateur en Europe", Groupe de Recherche European sur les Milieux Innovateurs (GREMI), Paris.

Azariadis, C. (1996). "The economics of poverty traps, part one: complete markets", Journal of Economic Growth, 1 (4): 449-486.

Barca, F. (2009). "The Union and Cohesion Policy - Thoughts for Tomorrow", Transcript of the presentation at the Conference for the 5th Anniversary of Poland's Accession to the EU, Brussels (BE): November 4, 2009. Retrieved online on Jan. 21, 2013 at the URL

http://ec.europa.eu/regional_policy/archive/policy/future/pdf/2009_11_4_thoughts_tomorrow.pdf.

Basile, R., Capello, R. and Caragliu, A. (2012). "Technological interdependence and regional growth in Europe: proximity and synergy in knowledge spillovers", Papers in Regional Science, 91 (4): 697-722.

Becattini, G. (1992). "The Marshallian industrial district as a socio-economic notion", in Pyke, F., Becattini, G. and Sengenberger, W. (eds), "Industrial districts and inter-firm co-operation in Italy", International Institute for Labour Studies, Geneva, pp. 37-51.

Bellet, M., Colletis, G. and Lung, Y. (eds) (1993). "Economie de proximite”, Revue d'Economie Regionale et Urbaine 3 (special issue).

Bergh, J. C. J. M. van den, Nijkamp, P. and Rietveld, P. (1998). Recent advances in spatial equilibrium modelling: methodology and applications, Berlin (DE): Springer Verlag.

Boschma, R. (2005). "Proximity and innovation: a critical assessment", Regional Studies, 39 (1): 61-74.

Boschma, R.A. Minondo, A. and Navarro, M. (2012). "Related variety and regional growth in Spain", Papers in Regional Science, 91 (2): 241-256.

Broekel, T. and Boschma, R. (2012). "Knowledge networks in the Dutch aviation industry: the proximity paradox, Journal of Economic Geography, 12 (2): 409-433.

Cairncross, F. (1997). "The death of distance: how the communications revolution is changing our lives", Boston (MA): Harvard Business School Press. 
Camagni R (1991). "Local milieu, uncertainty and innovation networks: towards a new dynamic theory of economic space”, in Camagni R (ed.), Innovation networks: spatial perspectives, London (UK): Belhaven-Pinter, pp. 121144.

Capello, R. and Caragliu, A. (2012). "Proximities and the intensity of scientific relations", paper presented at the International Tinbergen Institute Workshop, 7-8May, 2012.

Capello, R. (2009). Spatial spillovers and regional growth: a cognitive approach", European Planning Studies, 17(5): 639-658.

Caragliu, A. and Del Bo, C. (2011). "Determinants of spatial knowledge spillovers in Italian provinces", SocioEconomic Planning Sciences, 45 (1): 28-37.

Caragliu, A. and Nijkamp, P. (2012). "The impact of regional absorptive capacity on spatial knowledge spillovers", Applied Economics, 44 (11): 1363-1374.

Caragliu, A. and Nijkamp, P. (2013). "Cognitive capital and islands of innovation: the Lucas growth model from a regional perspective", Regional Studies, forthcoming.

Casi, L. and Resmini, L. ( 2010). "Evidence on the determinants of foreign direct investment: the case of EU regions", Eastern Journal of European Studies, 1(2): 93-118.

Cohen, W.M. and Levinthal, D.A. (1990) “Absorptive capacity: a new perspective on learning and innovation", Administrative Science Quarterly, 35 (1): 128-152.

Coleman, J. S. (1988). "Social capital in the creation of human capital”, American Journal of Sociology, 94: S95-S120.

Crevoisier, O. (1996). "Proximity and territory versus space in regional science", Environment and Planning A, 28 (9): 1683-1697.

Eichler, M., Grass, M., Blöchliger, H. and Ott, H. (2005). “Determinants of productivity growth”, executive summary of the Research Program "Policy and regional growth", Basel Economics. Retrieved on the web at the URL http://www.bakbasel.ch/downloads/services/reports_studies/2006/200601_policy_and_growth_exec_sum.pdf

European Commission (2011). "Report from the Commission to the European Parliament and the Council: Seventh progress report on economic, social and territorial cohesion", retrieved online on Jan. 21 at the URL http://eurlex.europa.eu/LexUriServ/LexUriServ.do?uri=COM:2011:0776:FIN:EN:PDF.

European Commission CORDIS (2005) Fifth Framework Programme Database, Brussels.

Faggian, A. and McCann, P. (2006). "Human capital flows and regional knowledge assets: a simultaneous equation approach", Oxford Economic Papers, 58 (3): 475-500.

Fujita, M, Krugman, P. and Venables, A. (1999). "The spatial economy - cities, regions and international trade", Boston (MA): MIT Press.

Fukuyama, F. (1995). “Trust: the social virtues and the creation of prosperity”, New York (NY): Free Press.

Geenhuizen, M.S. van and Nijkamp, P. (2012). "Knowledge virtualization and local connectedness among smart hightech companies", Technological Forecasting and Social Change, 79 (7): 1179-1191.

Grosjean, P. (2011). “The weight of history on European cultural integration: a gravity approach", paper presented at the 2011 Meeting of the American Economic Association.

Guiso, L., Sapienza, P. and Zingales, L. (2009). “Cultural biases in economic exchange?,” The Quarterly Journal of Economics, 124 (3): 1095-1131.

Howells, J.R.L. (2002). “Tacit knowledge, innovation and economic geography”, Urban Studies, 39 (5-6): 871-884.

Hüber, F. (2011). "On the role and interrelationship of spatial, social and cognitive proximity: personal knowledge relationships of R\&D workers in the Cambridge IT Cluster", Regional Studies (forthcoming). 
Isard, W. (1956). "Location and space-economy; a general theory relating to industrial location, market areas, land use, trade, and urban structure", Cambridge (MA): MIT Press.

Jaffe, A. B. and Trajtenberg, M. (1999). “International knowledge flows; evidence from patent citations”, Economics of Innovation and New Technology, 8 (1): 105-136.

Jaffe, A. B., Trajtenberg, M. and Henderson, R. (1993). “Geographic localization of knowledge spillovers as evidenced by patent citations", The Quarterly Journal of Economics, 108 (3): 577-598.

Johnson, B., Lorenz, E. and Lundvall, B.-A (2002). "Why all this fuss about codified and tacit knowledge?”, Industrial and Corporate Change, 11(2): 245-262.

Krugman, P. (1998). "Space: the final frontier”, Journal of Economic Perspectives, 12 (2): 161-174.

Loko, B. and Diouf, M. A. (2009). "Revisiting the determinants of productivity growth: what's new?", International Monetary Fund Working Paper WP/09/225.

Lucas, R. E. (1988). “On the mechanics of economic development”, Journal of Monetary Economics, 22 (1): 3-42.

Lundvall, B.-Å. and Johnson, B. (1994). "The learning economy”, Journal of Industry Studies, 1 (2): 23-42.

Maggioni, M. (2002). "Clustering dynamics and the location of high-tech firms", Ph.D. dissertation, University of Warwick.

Maggioni, M. and Uberti, E. (2009). “Knowledge networks across Europe: which distance matters?”, Annals of Regional Science, 43 (3), 691-720.

Maggioni, M., Nosvelli, M. and Uberti, E (2007). "Space versus networks in the geography of innovation: A European analysis", Papers in Regional Science, 86 (3): 471-493.

Marrocu, E., Paci, R. and Usai, S. (2011). "Proximity, networks and knowledge production in Europe", CRENOS WP 2011_09.

McCloskey, D. and Klamer, A. (1995). “One quarter of GDP is persuasion”, The American Economic Review, 85 (2): 191-195.

Morgan, K. (1997). “The learning region: institutions, innovation and regional renewal”, Regional Studies, 31 (5): 491503.

Orlando, M.J. (2004). "Measuring spillovers from industrial R\&D: on the importance of geographic and technological proximity, The RAND Journal of Economics, 35 (4): 777-786.

Padilla-Pérez, R. (2008). “A regional approach to study technology transfer through foreign direct investment: the electronics industry in two Mexican regions", Research Policy, 37, 849-860.

Perrin, J.C. (1995). "Apprentissage collectif, territoire et milieu innovateur: un nouveau paradigme pour le développement", in J. Ferrão (ed.), Políticas de Inovação e Desenvolvimento Regional et Local, Edição do Instituto de Ciencias Sociais de Universidade de Lisboa: Republished in R. Camagni and D. Maillat (eds) (2006), Milieux Innovateurs (pp. 99-128), Paris: Economica-Anthropos.

Polanyi, M. (1967). “The tacit dimension”, London (UK): Doubleday \& Co.

Ponds, R., Oort, F. V. and Frenken, K. (2010). "Innovation, spillovers and university-industry collaboration: an extended knowledge production function approach", Journal of Economic Geography, 10 (2): 231-255.

Putnam, R. D. (2000), Bowling alone, New York (NY): Simon and Schuster.

Putnam, R. D., Leonardi, R. and Nanetti, R. (1993). "Making democracy work: civic traditions in modern Italy", Princeton (NJ): Princeton University Press.

Scherngell, T. and Barber, M. J. (2009). "Spatial interaction modelling of cross-region R\&D collaborations: empirical evidence from the 5th EU Framework Programme", Papers in Regional Science, 88 (3): 531-546. 
Scherngell, T. and Barber, M. J. (2011). "Distinct spatial characteristics of industrial and public research collaborations: evidence from the fifth EU Framework Programme", The Annals of Regional Science, 46 (2): 247-266.

Shearmur, R. and Bonnet, N. (2011). "Does local technological innovation lead to local development? A policy perspective", Regional Science Policy and Practice, 3 (3): 249-272.

Suber, P. (2009). "Knowledge as a public good", SPARC Open Access Newsletter 139, downloaded on Apr. 2, 2012 at the URL http://www.earlham.edu/ peters/fos/newsletter/11-02-09.htm.

The American Heritage Dictionary of the English Language (2000). Fourth Edition, Boston (MA): Houghton Mifflin Company.

Torre, A. and Gilly, J.-P. (1999). “On the analytical dimension of proximity dynamics”, Regional Studies, 34 (2): 169 180.

Uphoff, N. (1999), "Understanding social capital: learning from the analysis and experiences of participation”, in P. Dasgupta and I. Seregeldin (eds), "Social capital: a multifaceted perspective", Washington (DC): World Bank.

Washington, H.A. (ed.) (1853). “The writings of Thomas Jefferson”, United States Congress, Vol. VI. 


\section{Technical Appendix}

\section{Details on the raw indicators used for estimating the Knowledge Production Function}

Table A1. Indicators and sources of raw data for the knowledge production function indicators

\begin{tabular}{lll}
\hline Variable & Indicator & Source of raw data \\
\hline Human capital & $\begin{array}{l}\text { Percentage of labour force with ISCED 5 } \\
\text { and 6 education }\end{array}$ & EUROSTAT \\
\hline Growth of accessibility & Growth of multimodal accessibility & ESPON database \\
\hline FDIs intensity & Count of FDI investments & Amadeus, raw data elaborated by \\
& & Laura Resmini (see for instance \\
Institutions & Casi and Resmini, 2010) & \\
\hline
\end{tabular}

\section{Details of the social capital indicator}

The results of the PCA performed in order to calculate social capital values in the EU27 regions are reported in Table A2 below. The social capital measure adopted here explains about 53 per cent of the total variance in the original data.

Table A2. Principal Component Analysis results forthe four social capital indicators

\begin{tabular}{lcccc}
\hline Variable & $\mathbf{1}$ & $\mathbf{2}$ & $\mathbf{3}$ & $\mathbf{4}$ \\
\hline \hline Share of people participating in clubs and voluntary associations & 0.26 & 0.96 & -0.03 & -0.02 \\
Share of people participating in any social activity & 0.62 & -0.19 & -0.05 & -0.76 \\
Share of people engaged in voluntary work & 0.54 & -0.16 & -0.65 & 0.51 \\
Share of people trusting other people & 0.51 & -0.10 & 0.76 & 0.39 \\
\hline Eigenvalue & 2.12 & 0.92 & 0.69 & 0.27 \\
Difference & 1.20 & 0.23 & 0.42 & - \\
Proportion & 0.53 & 0.23 & 0.17 & 0.07 \\
Cumulative & 0.53 & 0.76 & 0.93 & 1.00 \\
\hline
\end{tabular}

Source of raw data: European Values Study, Authors' calculation.

The first vector of the PCA, which summarizes more than half of the variance in the sample, is chosen as our measure of social capital. Regional variables are obtained by averaging out individual responses to questions

\footnotetext{
${ }^{21}$ Casi, L., and Resmini, L. ( 2010). "Evidence on the determinants of foreign direct investment: the case of EU regions", Eastern Journal of European Studies, 1(2): 93-118-118.
} 
administered in connection with the European Values Study (EVS). ${ }^{22}$ The questions (for each domain within the social capital definition) put to a sample of European citizens are reported in Table A3.

Table A3. Selected questions in the EVS data set

\begin{tabular}{|c|c|c|}
\hline Domain & Question & Scale \\
\hline \multirow{4}{*}{ Community organizational life } & \multirow{4}{*}{\multicolumn{2}{|c|}{$\begin{array}{l}\text { How often do you spend time in } 2 \text { once or twice a month } \\
\text { clubs and voluntary associations? } 3 \text { a few times a year } \\
\\
4 \text { not at all }\end{array}$}} \\
\hline & & \\
\hline & & \\
\hline & & \\
\hline Engagement in public affairs & $\begin{array}{l}\text { Do you participate in any form of } \\
\text { social activity? }\end{array}$ & $0-1$ \\
\hline Community volunteerism & $\begin{array}{l}\text { Do you take part in voluntary work } \\
\text { in any community activity? }\end{array}$ & $0-1$ \\
\hline \multirow{5}{*}{ Informal sociability } & \multirow{5}{*}{$\begin{array}{l}\text { Do you agree that "Most people can } \\
\text { be trusted" }\end{array}$} & 1 trust them completely \\
\hline & & 2 trust them a little \\
\hline & & 3 I neither trust nor distrust them \\
\hline & & 4 do not trust them very much \\
\hline & & 5 do not trust them at all \\
\hline
\end{tabular}

\section{Details on the technological proximity matrix}

Table A4 shows a list of the 2-digit manufacturing sectors whose location quotient has been calculated as a basis for identifying the technological distance matrix.

Table A4. NACE industries used in the calculation of the technological distance matrix.

\begin{tabular}{ll}
\hline Industry code & Industry name \\
\hline \hline DA & Food, beverages and tobacco \\
DBDC & Textiles and leather, etc. \\
DFDGDH & Coke, refined petroleum, nuclear fuel and chemicals, etc. \\
DL & Electrical and optical equipment \\
DM & Transport equipment \\
OM & Other manufacturing
\end{tabular}

Source of raw data: EUROSTAT, Authors' calculation.

\section{Details on the cognitive proximity matrix}

As Figure A1 shows, the formula adopted for calculating the cognitive proximity matrix implies that our indicator increases as the similarity of pairs of regions in patenting activity within 2-digit classes increases, while it decreases when regions share similar patenting profiles in 3-digit classes within each of the seven 2digit classes. Variations within 2- and 3-digit classes are complementary, so that our indicator takes on higher values when regions are, indeed, neither too close nor too distant in patenting profiles (Figure A1).

\footnotetext{
${ }^{22}$ EVS consists of a set of individual questionnaires administered to a sample of European citizens. Data have been collected in four waves: this paper uses the 1999-2000 wave, as it is the first to comprehensively cover the regional dimension of the analysis. For more information on how the data set was collected, and details on its representativeness in terms of regional, sex, and age characteristics, see http://www.europeanvaluesstudy.eu/
} 


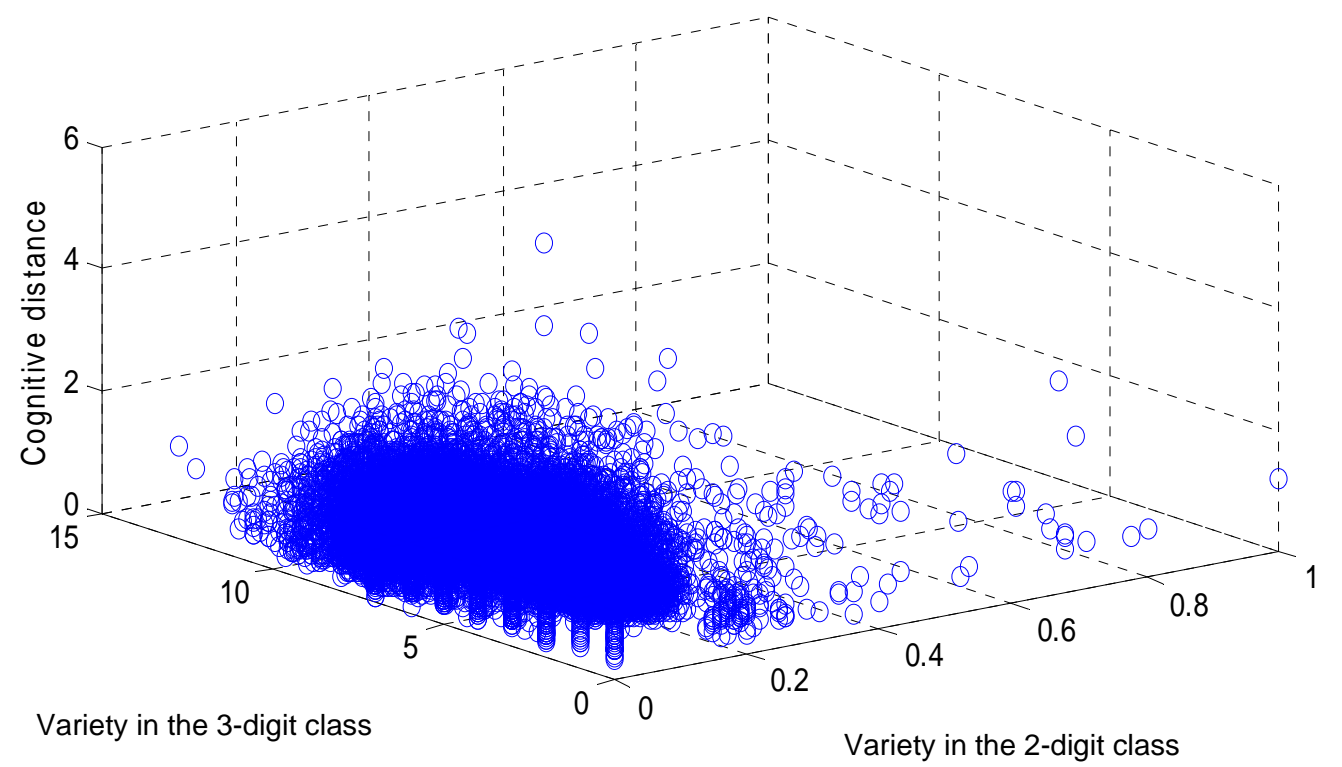

Figure A1. Variety in the 2- and 3-digit classes and measure of interregional cognitive proximity

Source: Authors' calculations.

\section{The geography of potential OKSs}

This section shows the whole set of maps (Figures A2-A6) of the five potential OKSs obtained with the transformation described in Section 3 of the paper, on the basis of the five proximity matrices used in the empirical sections. 


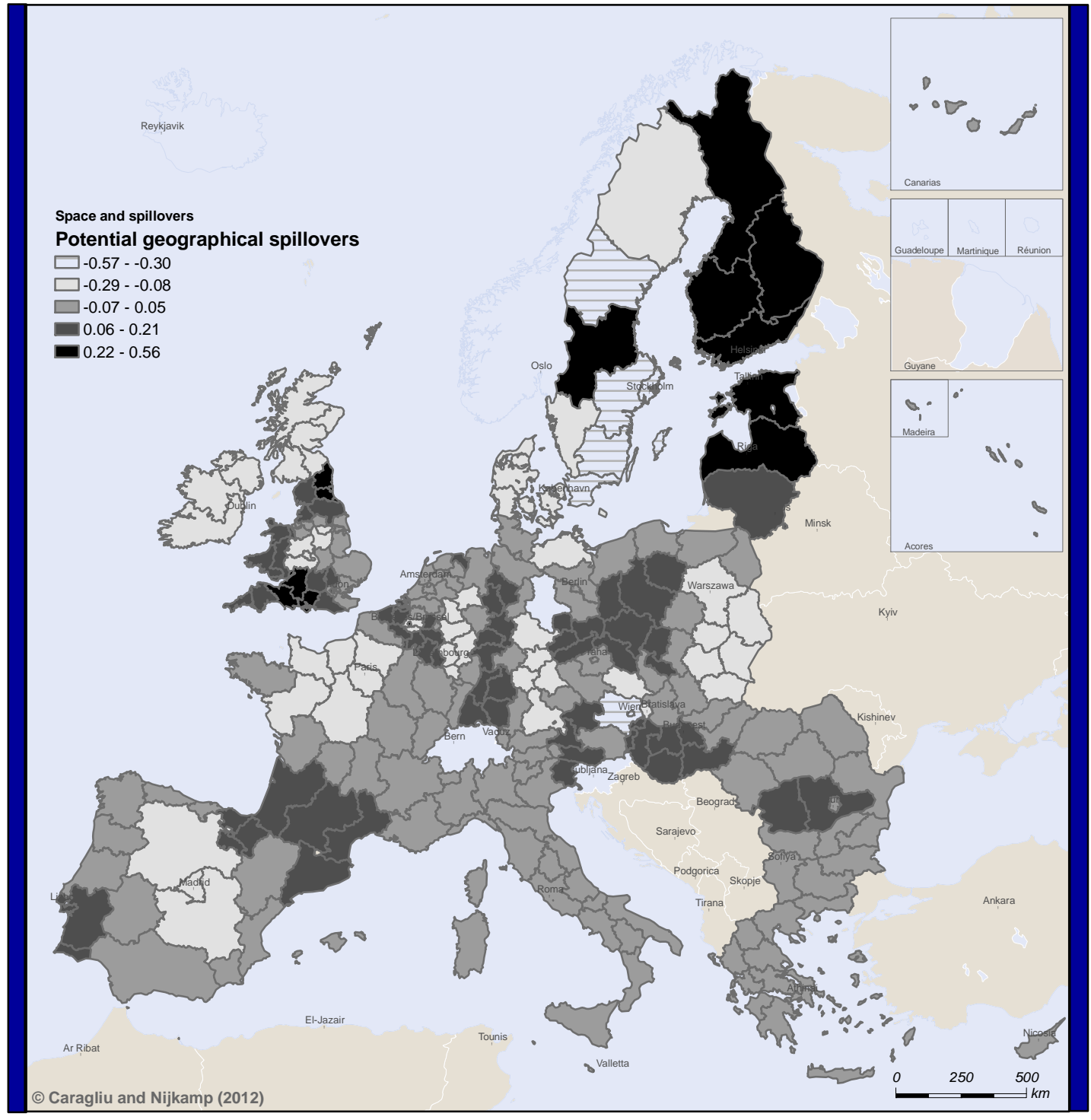

Figure A2. Potential KSs calculated with a spatial weight matrix 


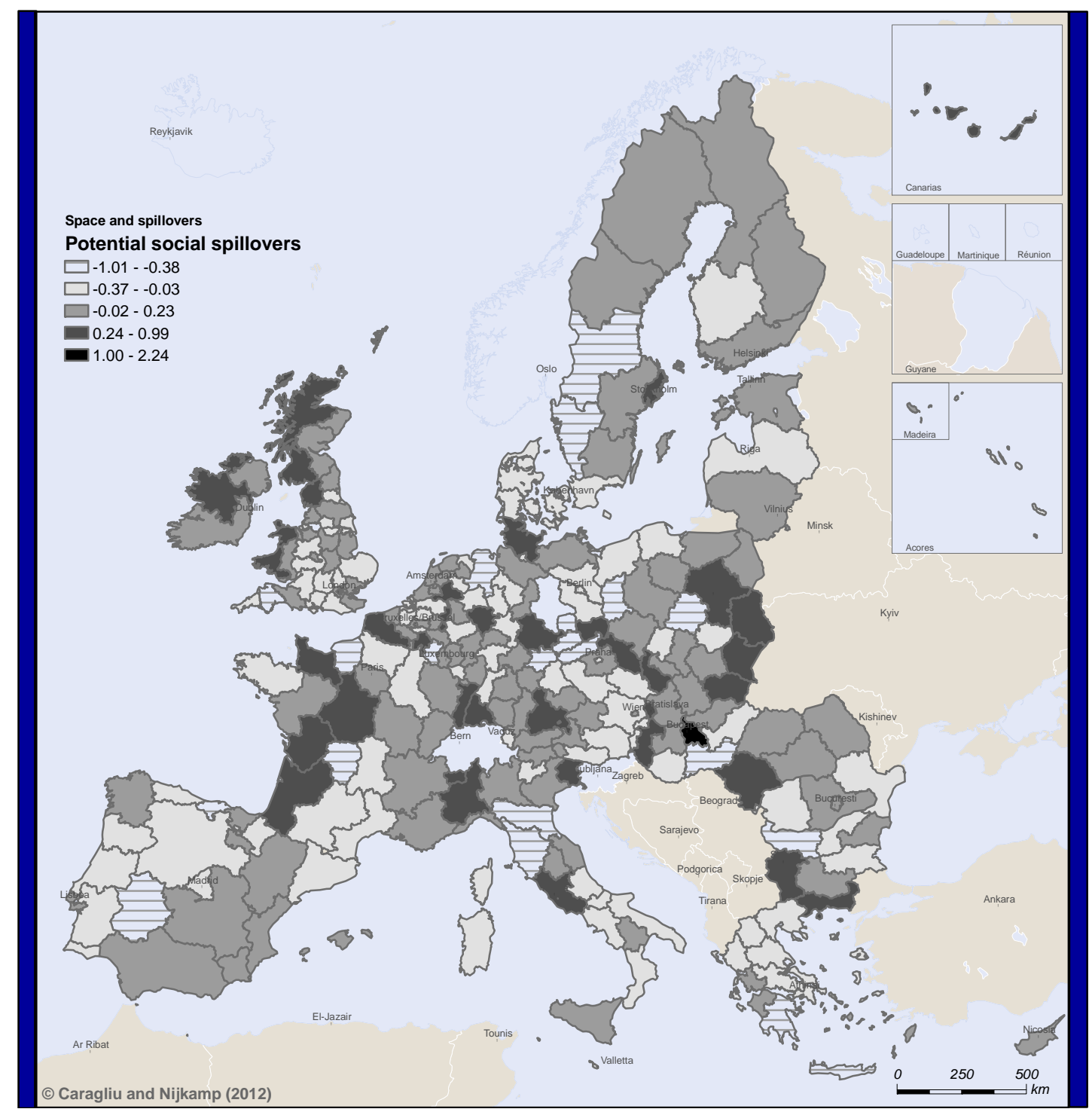

Figure A3. Potential KSs calculated with a social weight matrix 


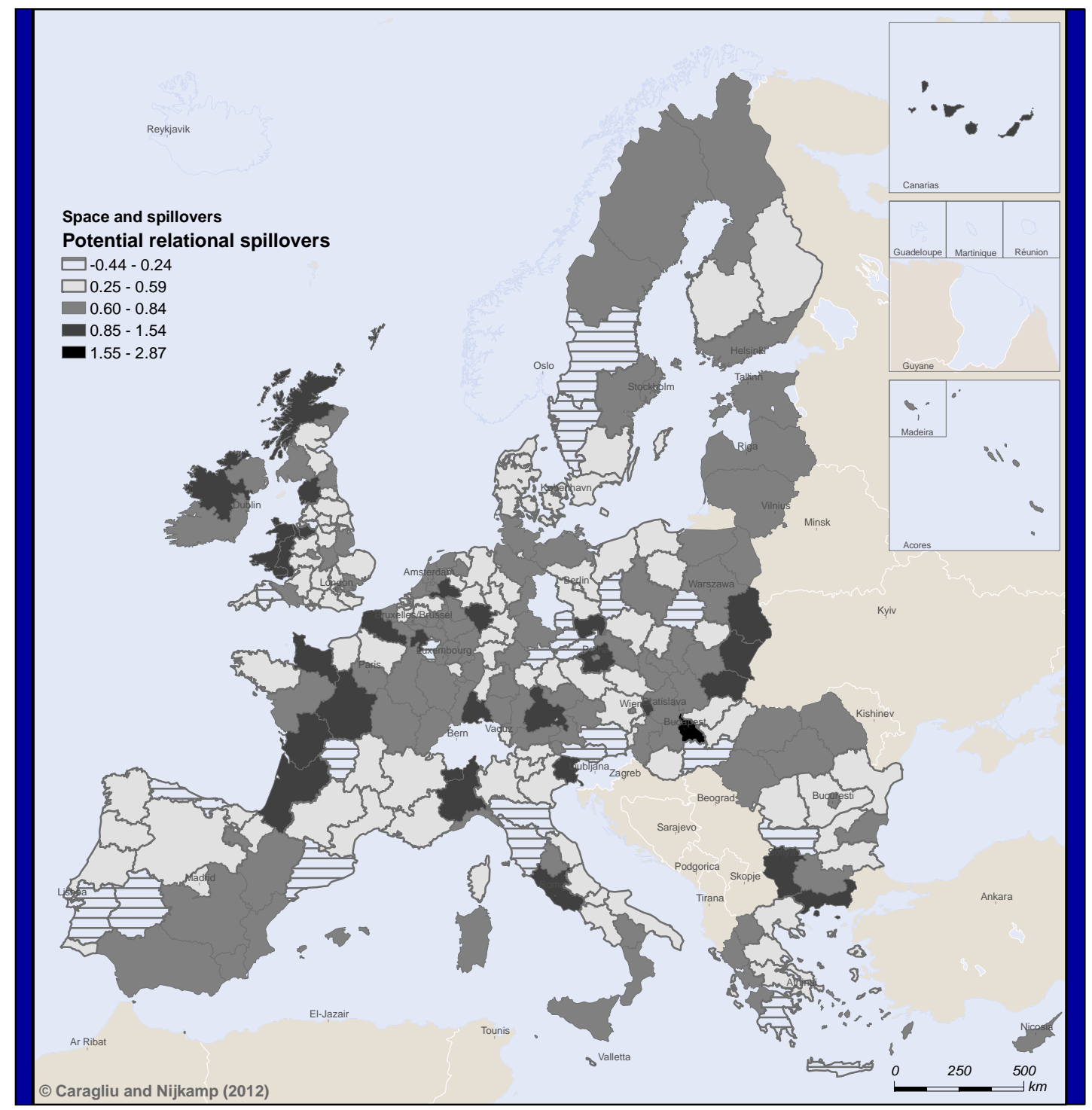

Figure A4. Potential KSs calculated with a relational weight matrix 


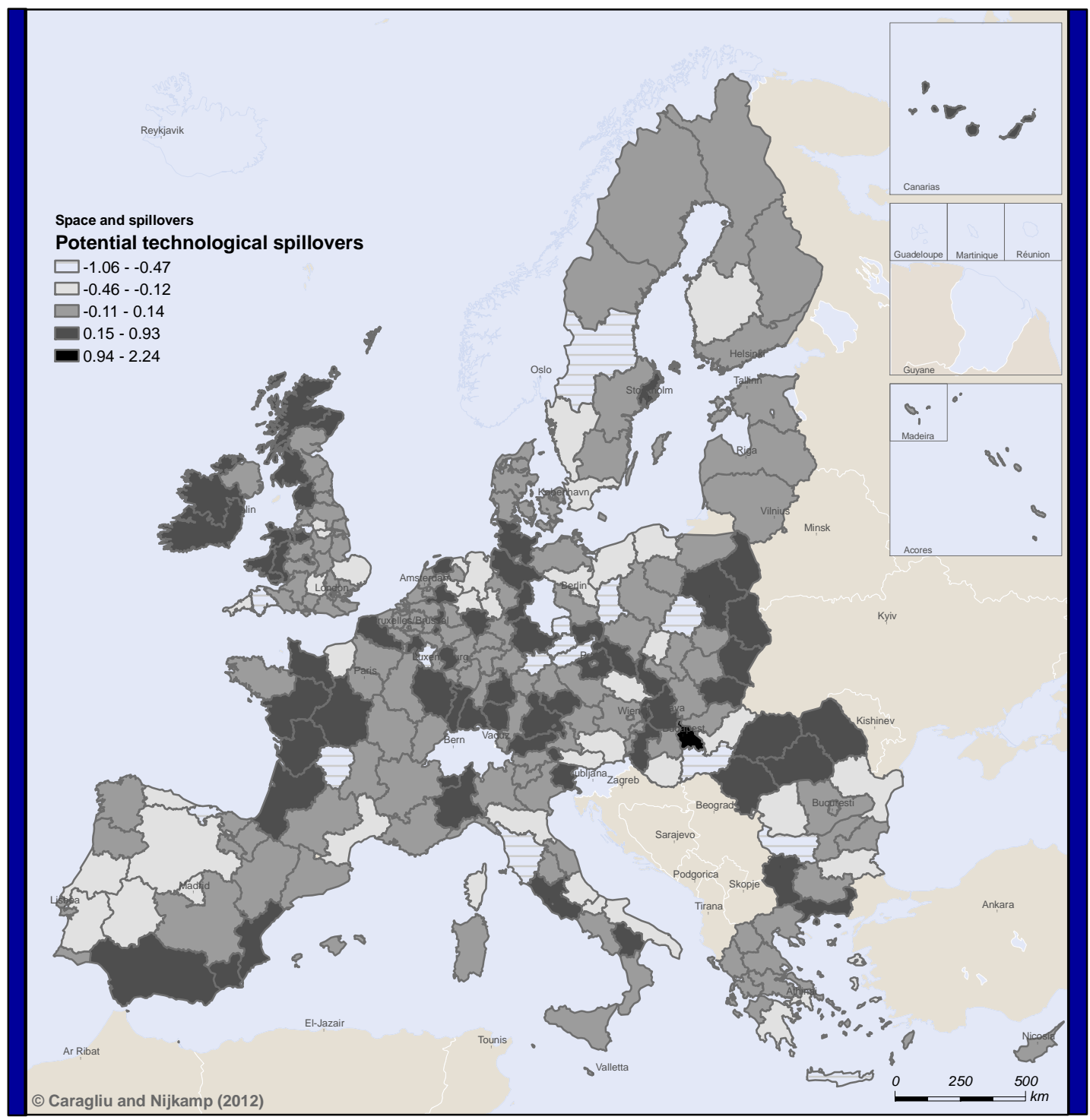

Figure A5. Potential KSs calculated with a technological weight matrix 


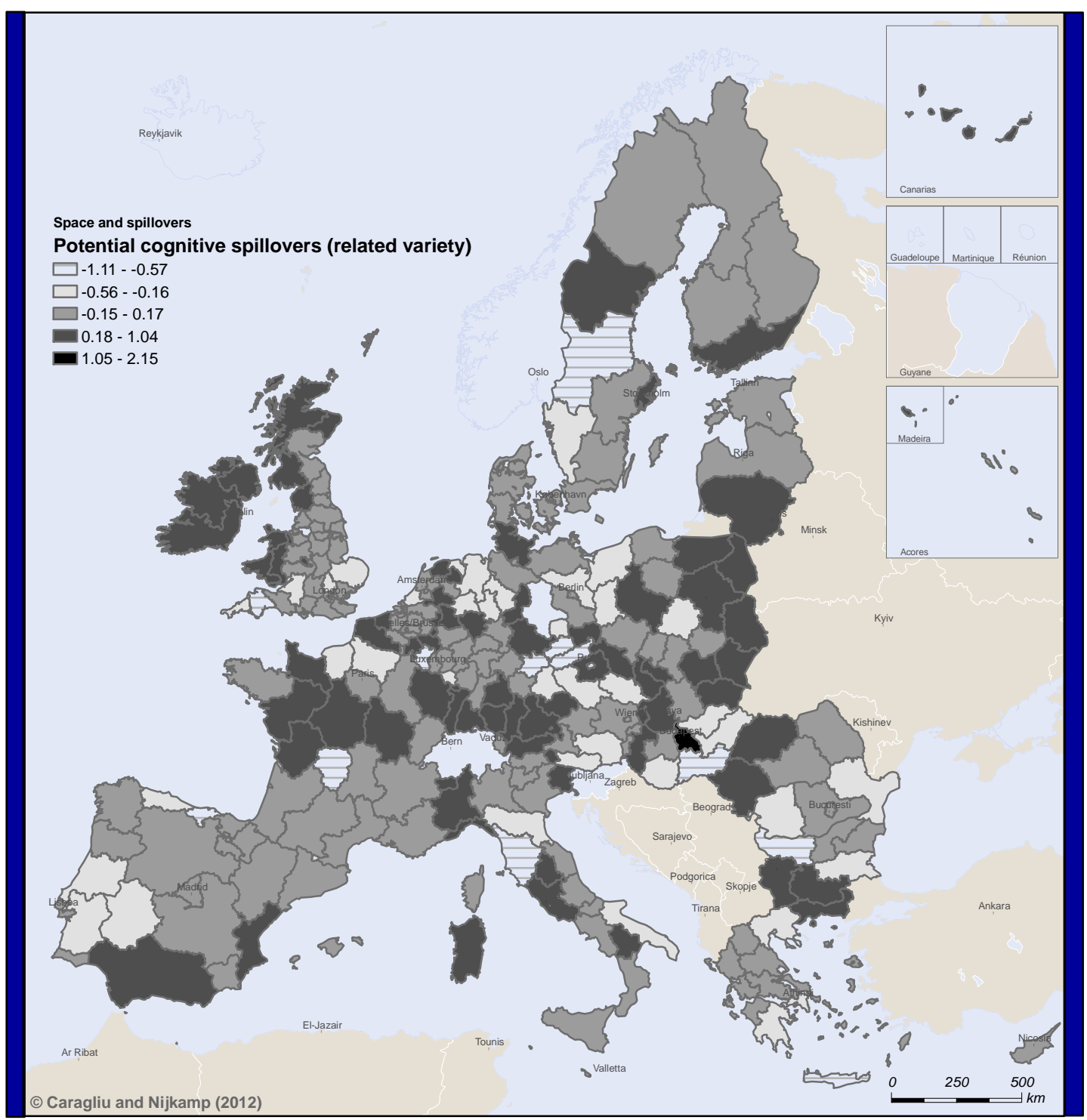

Figure A6. Potential KSs calculated with a cognitive weight matrix 


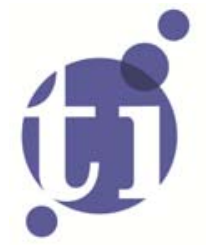

\title{
Space and Knowledge Spillovers in European Regions -
}

\section{The Impact of Different Forms of Proximity on Spatial Knowledge Diffusion}

\author{
Andrea Caragliur \\ Peter Nijkamp²
}

${ }^{\prime}$ Building Environment Science and Technology, Politecnico di Milano, Italy;

2 Faculty of Economics and Business Administration, VU University Amsterdam, and Tinbergen Institute, The Netherlands. 